\title{
FGF gene expression in injured tendons as a prognostic biomarker of 1-year patient outcome after Achilles tendon repair
}

\author{
Junyu Chen ${ }^{1}\left(\mathbb{D}\right.$, Joel Svensson ${ }^{1}$, Carl-Johan Sundberg ${ }^{2,3}$, Aisha Siddiqah Ahmed ${ }^{1}$ (D) and Paul W. Ackermann ${ }^{1 *}$ (D)
}

\begin{abstract}
Purpose: Healing outcome after Achilles Tendon Rupture (ATR) is variable and unsatisfactory. Many ATR patients still exhibit pain, functional deficits and limitations in walking one-year post-surgery. The present study was designed to investigate the association between the expression of healing biomarkers and patient outcome after ATR.
\end{abstract}

Methods: Tendon biopsies were collected from 25 ATR patients during surgery. At 1-year post surgery, all patients completed questionnaires; Achilles tendon Total Rupture Score (ATRS) and Foot and Ankle Outcome Score (FAOS), and were tested for functional outcomes by heel-rise test. In biopsies, FGF, COL III, FN, COL I and MMP-9 mRNA levels were assessed by quantitative RT-PCR while protein expression was studied by immunohistochemistry (IHC).

Results: Our analysis confirmed the presence of FGF, COL III, FN, COL I and MMP-9 at mRNA and protein levels in tendon biopsies. FGF gene expression associated positively with improved total ATRS and better functional outcomes. Additionally, FGF mRNA levels were associated with less pain, less running limitations and less loss in physical activity. In addition, higher COL III mRNA expression was associated with more tendon strength.

Conclusion: Our findings indicate that FGF gene expression is associated with improved patient-reported outcome. FGF expression in surgical biopsies could potentially be used to assist the prognostic evaluation of patient outcome and may be used as a predictor for healing. However, further studies are needed to evaluate the role of FGF in Achilles tendon healing.

Level of evidence: ॥

Keywords: Achilles tendon rupture, Patient outcome, Biomarkers, mRNA expression, immunohistochemistry

\section{Introduction}

Achilles tendon rupture (ATR) is a common injury which is increasing in incidence worldwide [21, 22, 32]. Patient outcomes are variable and patients are often plagued by pain and limitations in physical activities [29, 32, 37]. One important reason for the difficulties in improving the treatment of ATR is the lack of functional biomarkers which can be used as predictors of tendon healing.

\footnotetext{
* Correspondence: paul.ackermann@sll.se

'Department of Molecular Medicine and Surgery, Karolinska Institutet, 17176 Stockholm, Sweden

Full list of author information is available at the end of the article
}

Achilles tendon repair is a complex process which involves variety of cytokines, growth factors, proteases and collagens [38]. Growth factors released from bloodderived cells at the site of injury activate tissue-derived cells such as fibroblasts to start the production of extracellular matrix (ECM) proteins and proteases. Fibroblast growth factor (FGF), an inflammatory mediator released by blood-derived cells, is crucial for the initiation of healing processes in tendons mainly by stimulating proliferation of fibroblasts [30]. Moreover, FGF plays an important role in the synthesis of ECM protein and formation of granulation tissue in injured tendon [17].
Springer Open (c) The Author(s). 2021 Open Access This article is licensed under a Creative Commons Attribution 4.0 International License, which permits use, sharing, adaptation, distribution and reproduction in any medium or format, as long as you give appropriate credit to the original author(s) and the source, provide a link to the Creative Commons licence, and indicate if changes were made. The images or other third party material in this article are included in the article's Creative Commons licence, unless indicated otherwise in a credit line to the material. If material is not included in the article's Creative Commons licence and your intended use is not permitted by statutory regulation or exceeds the permitted use, you will need to obtain permission directly from the copyright holder. To view a copy of this licence, visit http://creativecommons.org/licenses/by/4.0/. 
However, the association between FGF and ATR healing as measured by patient-reported outcome has, to the best of our knowledge, not been studied before.

ECM deposition by fibroblasts especially during the early healing is rich in collagen III (COL III) [28], which is replaced by collagen I (COL I) during the later healing phases. The degradation of COL III and remodeling into COL I is performed by matrix metalloproteinases (MMPs), especially MMP-2 and -9 [9, 12, 14, 18]. Another protein, fibronectin (FN), has been reported to play crucial roles in tendon healing by arranging the matrix fibrils $[6,12]$. In addition, FN is reported to facilitate fibroblast adhesion, growth and migration in healing tendon [6]. The relationship, however, between collagens, proteases, FN and patient outcome after ATR healing is still unknown.

The aim of the study was to find potential biomarkers of tendon healing. For this purpose, the expression of FGF, COL III, FN, COL I and MMP-9 both at the mRNA and protein levels was studied in tendon biopsies collected from ATR patients and further the association between the expression of biomarkers and patient's outcome at 1-year post surgery was investigated. We hypothesized that the expression of healing biomarkers influences patient's long-term outcome and can be used as predictors of healing after ATR.

\section{Materials and methods}

This study was conducted with ethical approval from the Regional Ethical Review Committee in Stockholm, Sweden (Reference no. 2009/2079-31/2, 2013/1791-31/3). All participants provided written informed consent.

\section{Study design}

This is a retrospective study of twenty-five patients suffering with acute Achilles tendon rupture (ATR) who underwent reconstruction surgery at the local hospital. The majority of the ATR-cases, 90\%, were sportsrelated. During the surgery, tendon biopsies were taken from the ruptured and the intact area and stored at minus $80^{\circ} \mathrm{C}$ for future analysis. Patients were randomly selected from two patient cohorts who participated in randomized control trials. The patient outcome was evaluated 1-year postoperatively by using validated questionnaires; Achilles tendon Total Rupture Score (ATRS) and Foot and Ankle Outcome Score (FAOS). The functional outcomes were evaluated by using the heel-rise test (HRT).

\section{Inclusion and exclusion criteria for the patients}

The inclusion criteria were; patients diagnosed with acute Achilles tendon rupture at the Karolinska University Hospital. The exclusion criteria was; 1 ) unable to give verbal and/or written consent for participating in the study; 2) currently treated with anticoagulants; 3) allergic to contrast liquid; 4) planned follow up on other hospital than Karolinska University Hospital Solna; 5) unable to follow instructions; 6) patients suffering from renal failure; 7) patients with symptomatic chronic heart failure; 8) patients with thromboflebitis or known coagulation disorder; 9) patients had received other surgery during the month before tendon rupture; 10) patients with known malignancy or pregnancy.

\section{Surgical and biopsy procedure}

Local anesthetic was administered $\left(20 \mathrm{ml}\right.$ of Marcain ${ }^{\circ}$ and adrenalin $5 \mathrm{mg} / \mathrm{ml}$, AstraZeneca, London, UK) in the dermis, subcutis and peritendinous space prior to surgery. The patients were then placed in prone position and a medial incision was made through the skin, fascia cruris and paratenon. The rupture was located by the surgeon and a $10 \mathrm{~mm}$ Achilles tendon biopsy was taken from the ruptured area, another $10 \mathrm{~mm}$ biopsy was taken $3-4 \mathrm{~cm}$ away from the rupture side as a control, from a visibly intact tendon area.

A modified Kessler suture with two 1-0 polydioxanone (Ethicon, Somerville, New Jersey, USA) sutures, was used to bring the tendon ends together. The paratenon and fascia cruris were then closed with 3-0 Vicryl (Ethicon, Somerville, New Jersey, USA) and the skin was sutured with 3-0 Ethilon (Ethicon, Somerville, New Jersey, USA). The same anesthetic and surgical techniques were used for all patient using a predefined study protocol.

\section{Post-operative treatment}

All patients were prescribed paracetamol $500 \mathrm{mg}$ or codeine $30 \mathrm{mg}$ for administration if necessary, one to two pills at a maximum of four times per day. Patient included participated in two randomized trials evaluating post-operative treatments the first two post-operative weeks. None of the different post-operative treatments altered patient outcome at 1 -year post surgery $[1,4,10]$. The first study evaluated treatment in a below-knee plaster cast for 2 weeks compared to orthosis and adjuvant intermittent pneumatic compression [1]. The other study evaluated treatment in a below-knee plaster cast for 2 weeks compared to early weight bearing in an orthosis [4]. The remaining 4 weeks of immobilization all patients were prescribed full weight bearing in an orthosis.

\section{Patient reported outcomes}

Patient-reported outcomes were collected by using the ATRS and FAOS one-year post-operation during the follow up. ATRS consists of 10 sub-scales: strength in tendon, tiredness in the tendon, stiffness in tendon, pain in tendon, limitations in activity of daily life (ADL), limitation in uneven surface, stairs, running, jumping and 
loss in physical work [30]. Each sub-scale ranges from 0 to 10 where $0=$ worst and $10=$ best outcome with no limitation. The maximum ATRS is 100 , and a score higher than 80 was regarded as good subjective outcome.

FAOS consist of 5 categories: Pain, Symptoms, Activities of Daily Living, Sport and Recreational activities and Foot-and Ankle-Related Quality of Life [34]. Each category ranges from 0 to 100 where $0=$ worst and $100=$ best outcome, and a score higher than 80 was regarded as good subjective outcome.

\section{Functional outcome}

Functional outcomes were evaluated by heel-rise test (HRT) at 1-year post-surgery. HRT is a validated test $[25,36]$, which has been used in previous studies $[2,5$, 33 ] to show the outcome of strength and endurance of the affected gastrocnemius-soleus complex. The HRT was performed on one leg with the patient standing on a box with $10^{\circ}$ incline. The speed was set to 30 heel-rises/ min using a metronome. Patients were instructed to perform as high heel-rises as possible and as many heel-rise repetitions as possible. The test was terminated when the patient stopped or could not maintain the frequency. All the results, including the number of heel-rises, the height of every single heel-rise, the total work in joules (total distance $\times$ body weight), the time and the power (work/time) were recorded for analysis. The Limb Symmetry Index (LSI) was used to show the ratio between injured and contralateral uninjured leg and results are presented in percentage (injured/contralateral).

\section{mRNA extraction and tissue homogenization}

RNA was extracted from injured and intact tendon tissues collected from 20 subjects as described previously [31]. Briefly, the tissues were cut into small pieces at $20^{\circ} \mathrm{C}$, put into pre-cooled tubes with steal beads containing $1 \mathrm{ml}$ of tri-reagent (Sigma, Stockholm, Sweden) and immediately homogenized twice for $30 \mathrm{~s}$ by using a bead homogenizer [10] that shakes the tubes vigorously and ensures full homogenization. After addition of chloroform, samples were centrifuged to split into an aquatic and an organic phase. The aquatic phase was separated and precipitated with isopropanol to obtain
RNA as pellet. Glycogen was added for better visualization of RNA pellet, washed twice with ethanol, dried and re-dissolved in $10 \mu \mathrm{l}$ of RNase-free water.

\section{mRNA purification and quantitative real time-PCR (qRT- PCR) analysis}

The RNA quantification was determined using a Nanodrop ND-1000 spectrophotometer (Isogen Life Science, Sweden), and RNA quality was measured as the RNA quality index (RQI) using the Experion electrophoresis system (BioRad, Sweden). First-strand cDNA was synthesized from $50 \mathrm{ng}$ of total RNA using a firststrand cDNA Synthesis Kit (Roche, Germany).

For the qRT-PCR-analysis, RT-qPCR was performed using TaqMan Gene Expression Assays (Applied Biosystems, Carlsbad, CA) with the GeneAmp 7500 Fast Sequence Detection system (Applied Biosystems, Carlsbad, CA). Specific primers for FGF, COL III, FN, COL I, and MMP-9 (MWG Biotech, Ebersberg, Germany) were used to detect target genes (Table 1). Data was normalized by using GAPDH as the reference gene and $\triangle \triangle \mathrm{Ct}$ method was used for analysis.

\section{Histology \\ Fixation and staining}

Intact and injured tendon tissues from 5 subjects were fixed in Zamboni's fixative consisting of $4 \%$ paraformaldehyde in $0.2 \mathrm{~mol} / \mathrm{L}$ Sörensen phosphate buffer, $\mathrm{pH} 7.3$, containing $0.2 \%$ picric acid at $4{ }^{\circ} \mathrm{C}$ for $3-4$ days. Tissues were then soaked in $20 \%$ sucrose in $0.1 \mathrm{~mol} / \mathrm{L}$ Sörensen phosphate buffer, $\mathrm{pH} 7.2$, containing sodium azide and bacitracin (Sigma Chemicals, St. Louis, MO, USA). Subsequently, Tissues were sectioned using a Leitz 1720 cryostat (Ernst Leitz, Wetzlar, Germany) to a section thickness of $7 \mu \mathrm{m}$ and mounted on SuperFrost/Plus slides. For each slide, 2 sections; one from the injured and another from the uninjured were mounted. All the sections were stored at $-20^{\circ} \mathrm{C}$ until staining.

Sections were stained with hematoxylin and eosin (H\&E) and Sirius red following standard procedures. Images were captured by a video camera (DEI 750; Optronics Engineering, Goleto, CA) attached to the microscope and stored in a computer.

Table 1 Primers sequences (nucleotide sequences) used during quantitative RT-PCR

\begin{tabular}{lll}
\hline Genes & Forward Primer & Reverse primer \\
\hline FGF & TGACGGGTCCGGGAGAAGA & ATAGCCAGGTAACGGTTAGCACACAC \\
COL III & CACGGAAACACTGGTGGACAGATT & ATGCCAGCTGCACATCAAGGAC \\
FN & TITGCTCCTGCACATGCTTT & TAGTGCCTTCGGGACTGGGTTC \\
COLI & GGCAACAGCCGCTTCACCTAC & GCGGAGGACTTGGTGGTIT \\
MMP-9 & AGCGAGGTGGACCGGATGTT & AGAAGCGTCCTGGCAGAAATAG \\
GAPDH & CCTCCTGCACCACCAACTGCTT & GAGGGGCATCCACAGTCTTCT \\
\hline
\end{tabular}




\section{Immunohistochemistry (IHC)}

Sections were marked with pap-pen and soaked in $1 \%$ PBS for $5 \mathrm{~min}$ before incubation with $1 \% \mathrm{H}_{2} \mathrm{O}_{2}$ for $30 \mathrm{~min}$. Sections were then blocked with $2 \%$ goat or horse serum, washed with $1 \%$ PBS for $3 \times 5 \mathrm{~min}$ and incubated with Avidin and Biotin before overnight incubation with antibodies against FGF, COL III, FN, COL I and MMP-9 at room temperature. Sections were washed with $1 \%$ PBS for $3 \times 5$ min before incubating with $100 \mu \mathrm{l}$ secondary antibodies (1: 250, PBS-0.1\% BSA) for $40 \mathrm{~min}$. Secondary antibody, horse anti mouse was used for MMP-9, FN, FGF while for COL I and III, goat anti rabbit antibody was used. Slides were washed with $1 \%$ PBS for $3 \times 5$ min and incubated with $100 \mu \mathrm{l}$ of $\mathrm{ABC}$ solution (Vector Laboratories, Inc. Burlingame, CA, USA), stained with DAB solution (Vector Laboratories, Inc. Burlingame, CA, USA) and counterstained with
Hematoxylin (Vector Laboratories, Inc. Burlingame, CA, USA). This step was followed by dehydration in $70 \%, 96 \%$ and $100 \%$ alcohol and with the Xylene before mounting with pertex. To demonstrate specificity of staining, primary antiserum was either omitted or replaced by IgG. All the images were saved by the computer connected to the light microscope (DEI 750; Optronics Engineering, Goleto, CA, USA).

\section{Statistical analysis}

All data was analyzed using SPSS (IBM SPSS, version 24.0), and Graphpad Prism Software 8.0. Descriptive statistics (means $\pm \mathrm{SD}$ ) were used to summarize the variables. For normally distributed data Student's $t$-test was applied to detect differences among groups while the Mann-Whitney U-test was used for non-normally distributed data. The significance of correlation was

Table 2 Basic characteristics of subjects and their clinical information

\begin{tabular}{|c|c|c|c|}
\hline & Subscale & ATR Patients & ${ }^{\mathrm{a}}$ Residual symptom \% (n/N) \\
\hline Study subjects (N) & & 25 & \\
\hline Average Age (years \pm SD) & & $39.9 \pm 7.4$ & \\
\hline Gender (Male: Female) & & $12: 5$ & \\
\hline BMI $\left(\mathrm{kg} / \mathrm{m}^{2}\right)$ & & $25.6 \pm 3.1$ & \\
\hline TTS (hours) & & $67.0 \pm 29.1$ & \\
\hline \multirow[t]{11}{*}{ ATRS } & & $80.4 \pm 12.4$ & \\
\hline & Strength & $7.1 \pm 1.8$ & $100(17 / 17)$ \\
\hline & Tired & $7.4 \pm 2.3$ & $82.4(14 / 17)$ \\
\hline & Stiffness & $7.3 \pm 2.1$ & $82.4(14 / 17)$ \\
\hline & Pain & $9.5 \pm 0.8$ & $35.3(6 / 17)$ \\
\hline & $\mathrm{ADL}$ & $8.8 \pm 1.7$ & $58.8(10 / 17)$ \\
\hline & Surface & $9.2 \pm 1.3$ & $35.3(6 / 17)$ \\
\hline & Stairs & $8.8 \pm 1.2$ & $58.8(10 / 17)$ \\
\hline & Running & $7.2 \pm 2.4$ & $76.5(13 / 17)$ \\
\hline & Jumping & $6.1 \pm 2.7$ & $100(17 / 17)$ \\
\hline & Physical work & $9.0 \pm 1.4$ & $52.9(9 / 17)$ \\
\hline \multirow[t]{5}{*}{ FAOS } & Pain & $94.6 \pm 7.4$ & $52.9(9 / 17)$ \\
\hline & Symptom & $87.9 \pm 11.9$ & $76.5(13 / 17)$ \\
\hline & $A D L$ & $97.1 \pm 5.1$ & $64.7(11 / 17)$ \\
\hline & Sport and Recreation & $80.0 \pm 14.8$ & $88.2(15 / 17)$ \\
\hline & Foot-and Ankle-Related QOL & $74.5 \pm 15.4$ & $82.4(14 / 17)$ \\
\hline \multirow[t]{4}{*}{ HRT } & LSI Power & $83.1 \pm 13.2 \%$ & $88.2(15 / 17)$ \\
\hline & LSI Total work & $75.5 \pm 17.7 \%$ & $88.2(15 / 17)$ \\
\hline & LSI Repetition & $90.8 \pm 20.3 \%$ & $76.5(13 / 17)$ \\
\hline & LSI Average height & $83.8 \pm 12.4 \%$ & $94.1(16 / 17)$ \\
\hline
\end{tabular}

Demographic and clinical characteristics of ATR patients included in study. Data presented as mean \pm Standard Deviation. (BMI Body mass index, $T S$ Time to surgery, ATRS Achilles tendon Total Rupture Scale (0-100, and 0-10 for each subscale, worst $=0)$, FAOS Foot and Ankle Outcome Score $(0-100$, worst $=0$ for each

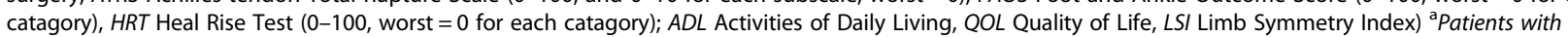
residual symptoms $(0-100$, worst $=100)$ were categorized as $\leq 99$ in ATRS, $\leq 9$ in ATR sub-scales, $\leq 99$ in FAOS and $\leq 99 \%$ in $H R T$ ratio. $n / N=$ number of patients/total number of study patients. 
determined by Spearman correlation co-efficient and effects of age, gender, BMI and TTS were determined by partial correlation analysis. A $p$-value $\leq 0.05$ was considered significant.

\section{Results}

\section{Patient characteristics}

The study included 25 patients with an average age $39.9 \pm 7.4$ years. Body mass index (BMI) was recorded as $25.6 \pm 3.1 \mathrm{~kg} / \mathrm{m}^{2}$ and time from injury to surgery (TTS) was $67.0 \pm 29.1 \mathrm{~h}$ (Table 2).

\section{Patient-reported outcomes}

Total mean ATRS was noted as $80.4 \pm 12.4$ at one-year post injury. ATRS subscales indicated that $35 \%$ of patients experienced pain to a small extent while more than $80 \%$ of the patients suffered from tiredness and stiffness in the tendon and experienced limitations in strength and jumping at 1-year post-surgery (Table 2).

FAOS indicated that $53 \%$ of the patients experienced a small degree of residual pain and more than $80 \%$ of the patients suffered of limitations in foot and ankle quality of life and in sports activities at 1-year post surgery (Table 2).

\section{Functional outcome}

At 1-year post-surgery, more than $80 \%$ of the patients experienced functional deficits in the injured side compared to the contralateral intact side using the HRT (Table 2).

\section{Gene expression analysis}

Our quantitative RT-PCR analysis showed that all studied genes were expressed in measurable levels in tissues collected from both intact and injured areas of the ruptured tendon. The expression was higher in injured areas compared to the visibly intact areas of the ruptured tendon, however, no statistically significant difference in the mRNA expression was observed for any of the genes (Fig. 1). Due to technical or handling complications, detectable RNA could be obtained from 12/20 patients.

\section{Association between gene expression and patient reported outcome}

The associations between mRNA expression of $F G F$, COL III, FN, COL I and MMP-9 in the injured tendon and ATRS and FAOS were studied. A positive association was observed between $F G F$ mRNA expression and total ATRS ( $r=0.711, P=0.048$ ) (Fig. 2) as well with ATR subscales of pain $(r=0.558, P=0.02)$, less running limitations $(r=0.733, P=0.007)$ and less loss in physical activity $(r=0.778, P=0.003)$ (Fig. 3a-c). No associations were observed between total ATRS or ATR subscales and either of COL III, FN, COL I or MMP-9 gene

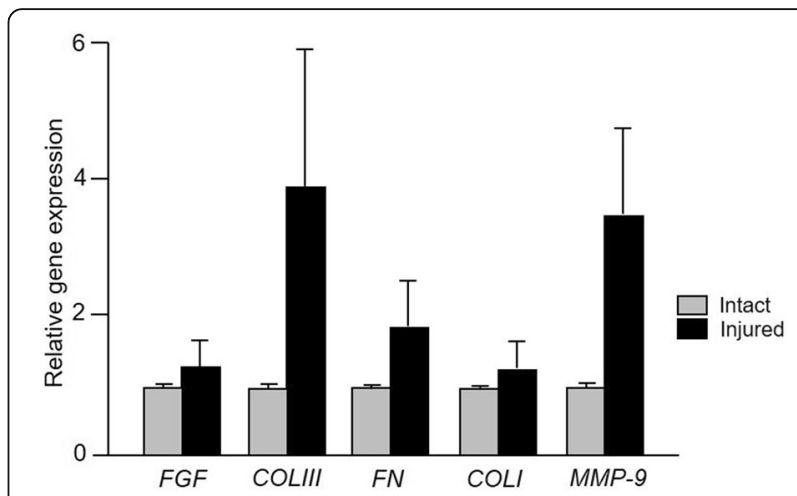

Fig. 1 Relative gene expression of Fibroblast growth factor (FGF), collagen III (COL III), fibronectin (FM), collagen I (COL I) and matrix metalloproteinase-9 (MMP-9) in biopsies collected from the injured and intact area of tendon. Values reported are mean $\pm \operatorname{SEM} n=12$

expression in the ATR patients except that of strength in the tendon which was positively correlated with higher COL III mRNA $(r=0.710, P=0.032)$ expression in the injured tendon (Fig. 3d). No effect of age, gender, BMI or TTS was noted for any of the associations.

No associations were observed between any of the FAOS categories and FN, COLIII, FN, COLI or MMP-9 gene expression in the ATR patients.

\section{Association between gene expression and HRT}

A positive association was observed between FGF gene expression in the injured tendon and LSI power $(r=$ $0.758, P=0.048)$ and LSI- average height $(r=0.8, P=$ 0.031) (Fig. 4a, b). No associations were found between repetitions or total work and either of COL III, FN, COL $I$ or $M M P-9$ gene expression in the ATR patients.

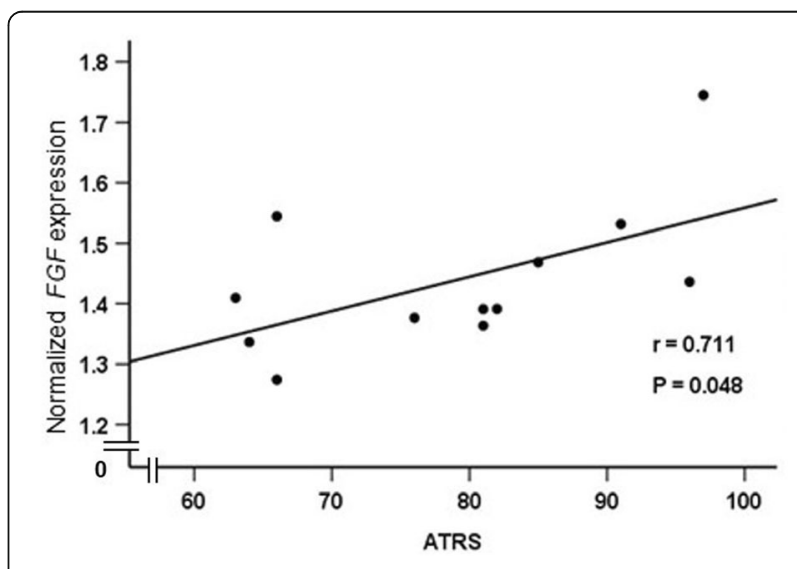

Fig. 2 Correlation between FGF mRNA expression and total ATRS as measured by Spearman's rank correlation coefficient. FGF mRNA expression was normalized and ATRS ranges from 0 to 100, with $100=$ best outcome. $n=12$ 

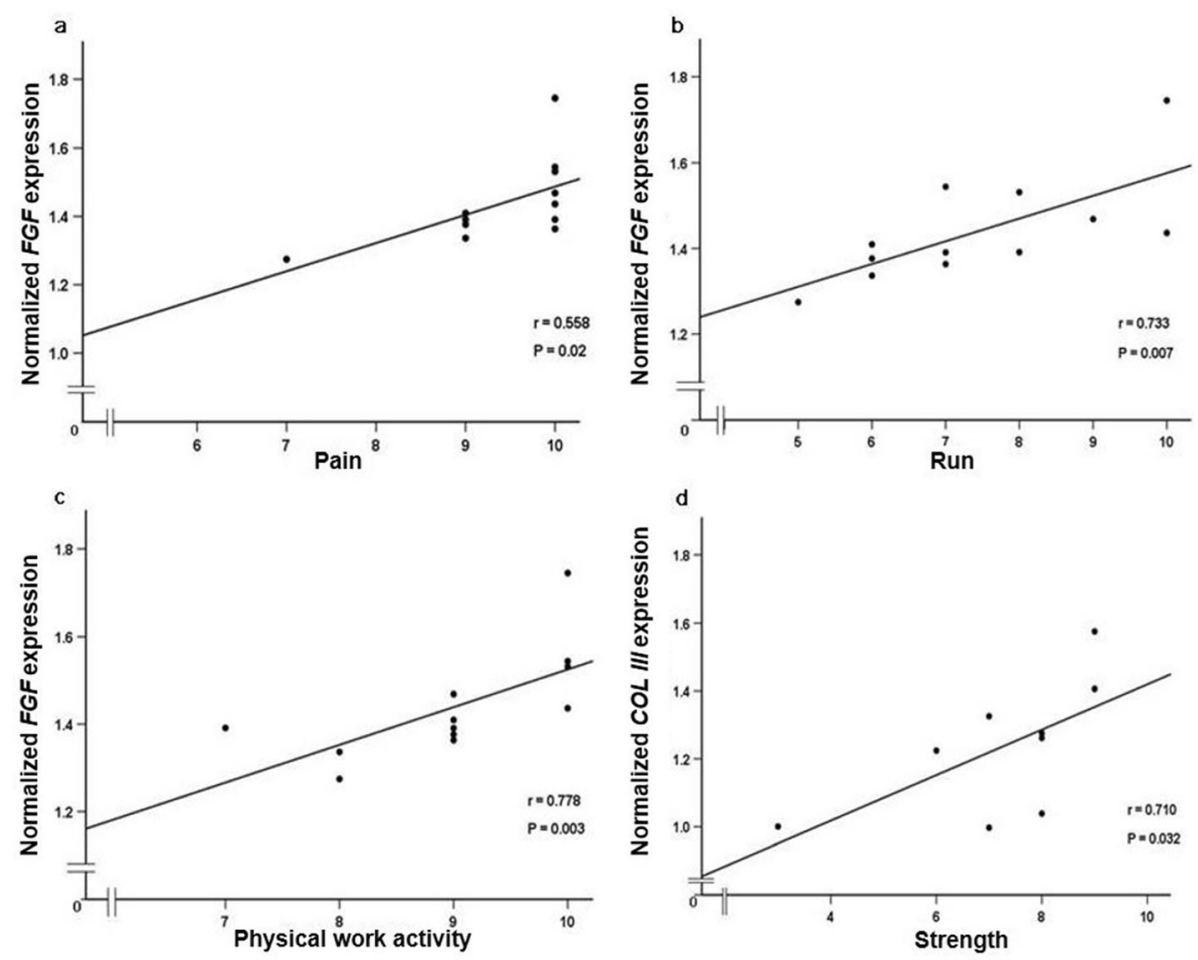

Fig. 3 Associations among biomarker mRNA expression and ATRS sub-scales. Correlations between a) FGF gene expression and pain, b) FGF gene expression and run, c) FGF gene expression and physical work activity and, d) COL III gene expression and strength measured by Spearman's rank correlation coefficient. ATRS sub-scales ranges from 0 to 10 , with $10=$ best outcome. $n=12$

\section{Associations among gene expression}

A positive association was observed between $F G F$ and $M M P-9$ gene expression $(\mathrm{r}=0.594, P=0.042)$ (Fig. 5a). No associations were observed for FGF and COL III, $F N$ or COL $I$ gene expression. Moreover, higher $M M P-9$ was found to have a positive association with higher COL $I(r=0.657, P=0.02)$ (Fig. 5b) and $F N$ $(r=0.643, P=0.024)$ gene expression (Fig. 5c). No association was observed among MMP-9 and COL III mRNA levels. Additionally, higher COL $I$ was positively associated with more $F N$ mRNA expression
( $r=0.664, P=0.018$ ) (Fig. $5 \mathrm{~d})$. No effect of age, gender, BMI or TTS was apparent for any of the associations. No associations were observed between COL I and FGF or COL III gene expression, and between $F N$ and FGF or COL III gene expression.

\section{Histological assessment}

Our histological analysis did not detect any obvious differences in protein amount of FGF, COL III, FN, COL I and $M M P-9$ between the injured and intact areas of the ruptured tendons, which was in line with the findings of
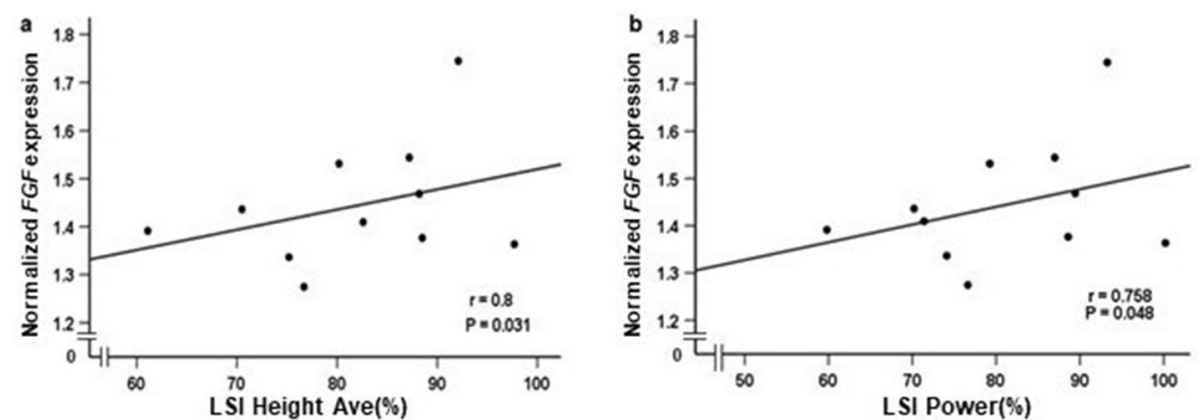

Fig. 4 Associations among biomarker gene expression and HRT categories. Correlations between (a) FGF gene expression and LSI average height and, b FGF gene expression and LSI power measured by Spearman's rank correlation coefficient. HRT categories ranges from 0 to 100 , with $100=$ best outcome. $n=12$ 

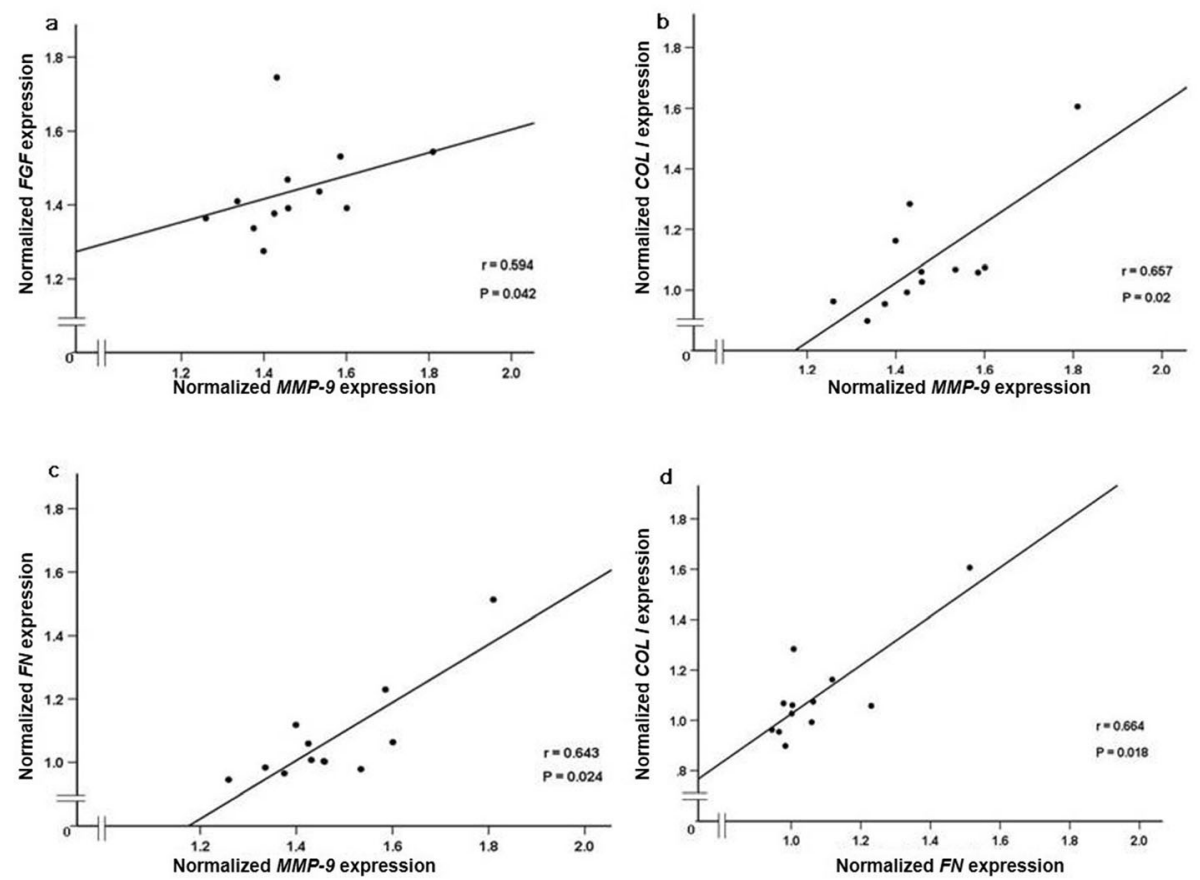

Fig. 5 Associations among gene expression of a MMP-9 and FGF, b MMP-9 and COL I, c MMP-9 and FN and, d FN and COL measured by Spearman's rank correlation coefficient. $n=12$

the gene expression analysis. However, tendon collagen fibers were continuous and aligned in a parallel manner in intact areas, while disordered and broken fascicles were observed in the injured areas of the tendon at the time of surgery (Fig. 6a-d).

\section{Localization and expression of biomarkers}

Overall, the immunohistochemical analysis of biomarkers at the protein level confirmed our finding of gene expression. However, a differential expression pattern and localization was observed for all studied biomarkers.
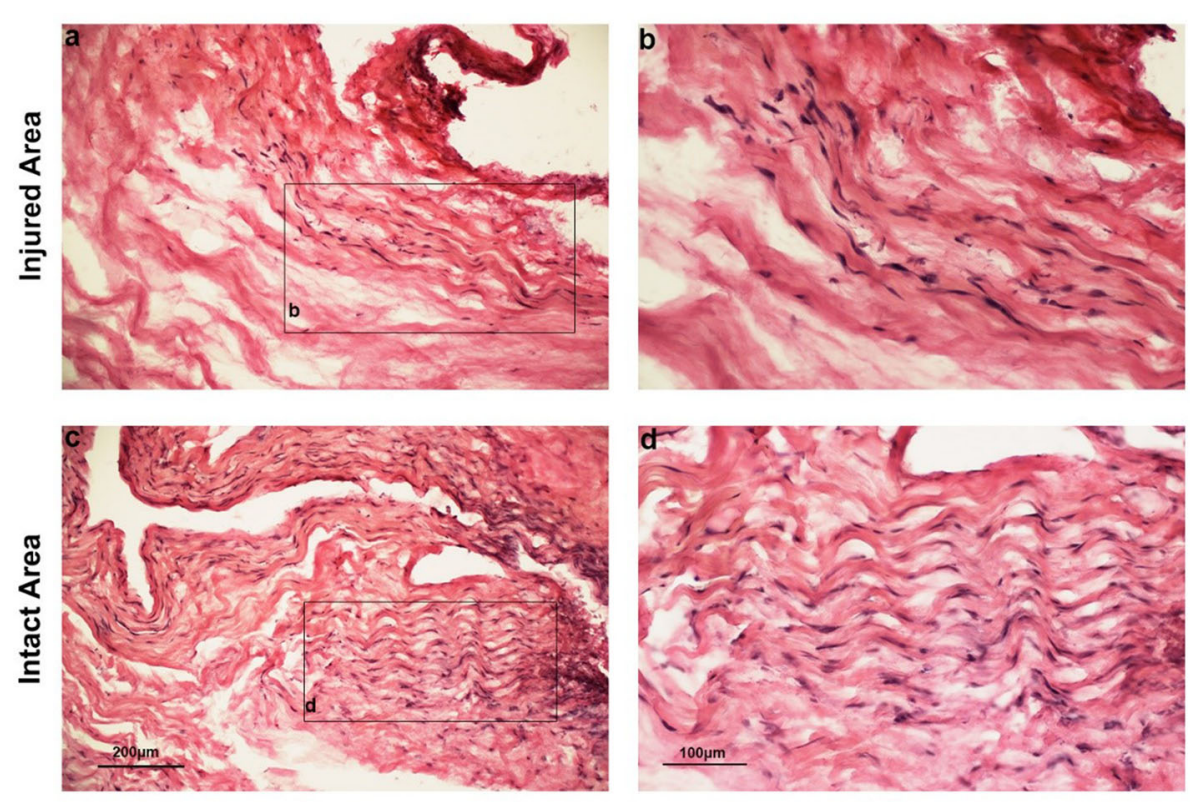

Fig. 6 Photomicrographs of the injured and intact Achilles tendon stained with haematoxylin and eosin (a-d). All images are representatives from 5 patients. Original magnification is 10x (a and $\mathbf{c}$ ) or 20X (b and $\mathbf{d}$ ) 
FGF

FGF was expressed dispersed in both the intrafascicular tendon matrix and in the surrounding interfascicular connective tissues (Fig. 7a-c). In intact tendon, FGF was expressed mostly in the interfascicular matrix (Fig. 7c), while in the injured tendon, FGF was predominantly expressed close to blood vessels in the interfascicular connective tissues, but also observed in the intrafascicular matrix (Fig. 7a-b).

\section{COL III}

COL III was expressed extensively in both intrafascicular matrix and interfascicular connective tissues (Fig. 7d-f). In the intact tendon areas, COL III protein expression was found in the intrafascicular matrix (Fig. 7f) while in the injured tendon, COL III expression was observed in the tendon matrix as well in the interfascicular connective tissues (Fig. 7d-e).

\section{FN}

In intact tendon, $\mathrm{FN}$ expression was observed in the interfascicular matrix (Fig. 7g-h) while strong FN staining was observed both in intrafascicular matrix and in interfascicular connective tissues in the injured tendon areas (Fig. $7 \mathrm{~g}-\mathrm{h}$ ).

\section{Col I}

Generally, COL I was expressed in both interfascicular connective tissues and intrafascicular matrix in biopsies (Fig. 7j-1). In intact areas, COL I was expressed in the

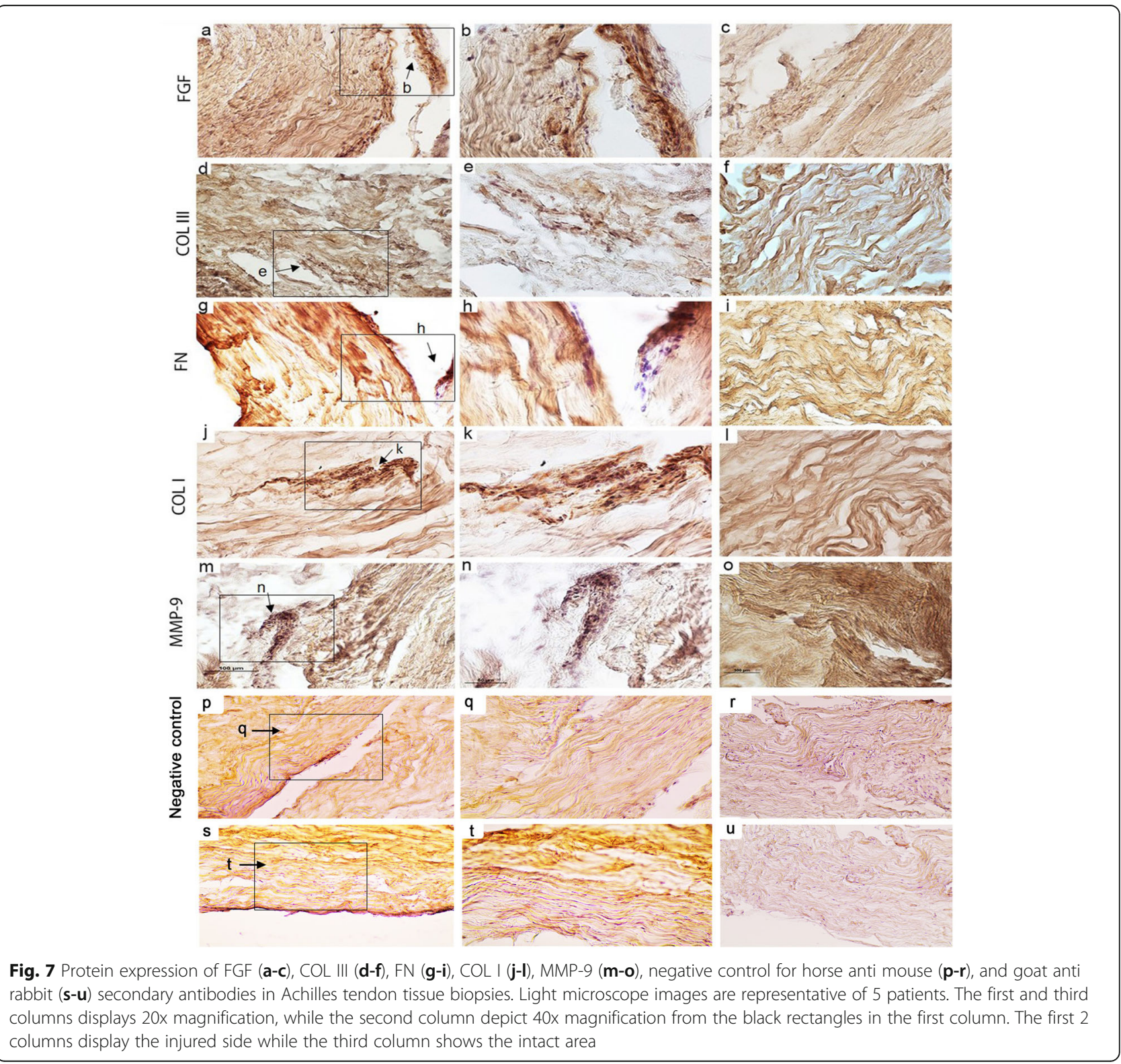


intrafascicular matrix (Fig. 7l), while in the injured areas, COL I expressed both in the interfascicular connective tissues and the intrafascicular matrix (Fig. 7j-k).

\section{MMP-9}

In the intact tendon weak MMP-9 staining was found in the intrafascicular matrix (Fig. 7o). However, in the injured areas, $M M P-9$ expression was mainly seen in the interfascicular connective tissues observed close to blood vessels (Fig. $7 m-n$ ).

\section{Discussion}

To be best of our knowledge, the results of this study indicate for the first time that FGF gene expression in surgical tendon biopsies could be of importance as predictors to assist evaluation of ATR patient outcome 1 year post surgery. We found that higher FGF mRNA expression was correlated to improved patient outcome: less pain, less running limitations, less loss in physical work activity, more heel-rise height and more heel-rise power. Moreover, higher COL III gene expression was associated with increased tendon strength. Taken together, our results demonstrate that biomarker gene expression can be associated with long term patientreported outcome in ATR patients.

The most important finding was that higher FGF gene expression was positively correlated to better patientreported outcome 1 year after ATR, which could suggest an overall improved tendon healing process. The positive association between FGF mRNA expression and functional outcome strengthens our finding of improved tendon repair. Tendon healing is influenced by numerous processes such as cellular migration and proliferation, tissue remodeling, and synthesis of ECM, all these stages are orchestrated by variety of biomarkers $[14,16]$. FGF is a multifunctional biomarker with several positive influences on tendon healing that have been demonstrated in previous studies [23, 39]. FGF initiates and stimulates the proliferation and migration of fibroblasts, i.e. in tendon so called tenoblasts, which are the important cells synthesizing new collagens. Our finding of higher FGF expression associated with better patientreported outcome may be related to increased collagen production. In addition, a previous study showed that FGF can influence stem cells to express tendon-related genes, such as Collagen type I and III [13]. The increased FGF expression as observed in the present study, in injured Achilles tendon, presumably activates the production of COL I and III to improve the coding process of collagens, and also regulates the balance between ECM degradation and synthesis, leading to improved healing outcome. Moreover, FGF has been reported to strengthen the biomechanical properties in regenerative tendon by up-regulating the production of
COL I and III [7]. Additionally, FGF has been identified to increase tendon healing by stimulating the orientation of collagen fibers and improving the biomechanical properties in a rabbit model of tendon healing [27]. No associations were found between the gene expression of the other four biomarkers examined and ATRS, indicating that FGF has a more essential role in long-term healing than the other biomarkers.

Increased FGF gene expression was associated with ATRS subscales of decreased pain, less running limitation and less loss in physical activity. Limitations in motion and loss of physical activity are two essential factors, which impact the quality of daily life for ATR patients after surgery. Pain may be one of the most important issues for ATR patients during the healing process. As reported previously, 44\% of ATR patients exhibited pain in their injured leg 1 year after surgery [37], which impacts most of their daily life. Patients with ATR exhibit limitations in running, jumping, walking and loss of physical activity as well $[11,15,26]$. Pain is the main factor regulating the physical activity level in ATR patients. This may be the explanation for the simultaneous improvement in pain, running limitations and loss in physical activity as observed in the present study. Our study showed that higher FGF gene expression in human tendon was positively correlated to less pain, less running limitations and less loss in physical work activity. The comprehensive influence of FGF on the long-term patient-reported outcome reflects a multifunctional importance of FGF as a biomarker in tendon healing.

The second most important finding of this study was that higher COL III gene expression was associated with increased tendon strength. The healing process after ATR is slow and the content of collagens is changing during the initial inflammatory to later remodeling phase [3]. Tendons are mainly composed of collagen type I and III. COL I is the predominant type in normal tendon and make up bundles of thick fibrils [19], which maintain the tensile stiffness of the tendon. In contrast, COL III produces loosely packed bundles of thin fibers, so called scar tissue [8]. COL III is widely expressed among COL I bundles and is more flexible than COL I [35]. Conceivably, the increased COL III gene expression reflects more collagen type III production in the tendon at the time of surgery, which was at a mean of 3 days post rupture, i.e. early healing. We therefore suggest that the COL III gene expression is reflective of granulation/scar tissue repair in the early healing phase before the shift to COL I production has taken place.

Another interesting finding of our study was the positive association between FGF and MMP-9 at the mRNA level. Earlier studies have reported on the interaction of FGF and MMPs in modulating tissue repair [20, 40]. In addition, FGF has been reported to facilitate the ECM 
remodeling and turnover by regulating the activation and synthesis of MMPs in mouse tendon repair [17]. Taken together, the results of the present study strengthen the previous observations of a strong biomodulatory connection between FGF and MMPs during tendon healing.

Our observation of $M M P-9$ mRNA levels being positively associated with $C O L I$ and $F N$ gene expression are in line with earlier findings. Increased MMP-9 and COL I protein expression have previously been reported in relation to the early healing process [24]. We further observed associations between gene expression of $C O L I$ and $F N$ in injured Achilles tendon, which may seem logical based on their interaction in the healing process. We did, however, not find any association between $M M P-9, C O L I, F N$ and patient outcome. The reasons for these three genes not being correlated with patient outcome may be due to factors such as the timing of biopsy taking or to the fact that they do not have the same strong influence as FGF on patient outcome.

A potential limitation of this study is that we could not extract RNA from all studied subjects included in the study due to technical problems. The association between mRNA and outcome is not equal to an association between the protein and outcome, since transcriptional or post-translational regulation may change the protein expression. Based on limited number of samples, we did not fully explore the effects of age, sex, BMI or TTS on the associations among gene expression and ATRS subscale. However, the effects of age, sex, BMI and TTS were considered in the statistical analyses. Therefore, the identified associations should be considered as exploratory with the aim to identify promising therapeutic targets and need to be replicated in other larger studies.

\section{Conclusion}

Taken together, our findings provide evidence that FGF expression in tendon biopsies of patients with acute ATR, can be used as predictor for prognostic evaluation of patient outcome, one-year post-surgery. Our findings also provide a foundation for the future development of FGF based novel therapies to improve healing after connective tissue injuries.

\footnotetext{
Acknowledgements

The present study was supported by the grants from the Swedish National Centre for Sports Research (project no. P2019-0079 (ASA) and P2017-0111 (PWA)), the Stockholm County Council to PWA (project no. SLL20150435), and the Swedish Research Council to PWA (project no. 2012-3510). There was no role for any funding agency regarding the study design, collection and analysis, interpretation of data, manuscript writing or in the decision to submit the manuscript for publication.
}

\section{Authors' contributions}

JC participated in the study design, interpretation of data, statistical analysis, experiment, manuscript writing and reviewing. JS performed part of the experiment in the lab and took part in data collection. CJS participated in reviewing of the manuscript. ASA participated in the study concept and design, reviewed and adjusted the manuscript as well. PWA participated in the study concept and design, interpretation of data, manuscript reviewing and the study supervision. The authors read and approved the final manuscript.

\section{Ethics approval and consent to participate}

This study was conducted with ethical approval from the Regional Ethical Review Committee in Stockholm, Sweden (ID nr. 2013/1791-31/3 and 2009/ 2079-31/2). All the subjects in the present study obtained informed consent and the study was approved by the Institutional Review Board.

\section{Competing interests}

There is no financial or other relationship that may cause a conflict of interest.

\section{Author details}

${ }^{1}$ Department of Molecular Medicine and Surgery, Karolinska Institutet, 17176 Stockholm, Sweden. ${ }^{2}$ Department of Physiology \& Pharmacology, Karolinska Institutet, Stockholm, Sweden. ${ }^{3}$ Department of Learning, Informatics, Management and Ethics, Karolinska Institutet, Stockholm, Sweden.

Received: 30 September 2020 Accepted: 11 February 2021

Published online: 11 March 2021

References

1. Alim MA, Domeij-Arverud E, Nilsson G, Edman G, Ackermann PW (2018) Achilles tendon rupture healing is enhanced by intermittent pneumatic compression upregulating collagen type I synthesis. Knee Surg Sports Traumatol Arthrosc 26:2021-2029

2. Alim MA, Svedman S, Edman G, Ackermann PW (2016) Procollagen markers in microdialysate can predict patient outcome after Achilles tendon rupture. BMJ Open Sport Exerc Med 2:e000114

3. Aro AA, Simoes GF, Esquisatto MA, Foglio MA, Carvalho JE, Oliveira AL et al (2013) Arrabidaea chica extract improves gait recovery and changes collagen content during healing of the Achilles tendon. Injury 44:884-892

4. Aufwerber S, Heijne A, Edman G, Silbernagel KG, Ackermann PW (2020) Does early functional mobilization affect long-term outcomes after an Achilles tendon rupture? A randomized clinical trial. Orthop J Sports Med $8(3)$

5. Bostick GP, Jomha NM, Suchak AA, Beaupre LA (2010) Factors associated with calf muscle endurance recovery 1 year after achilles tendon rupture repair. J Orthop Sports Phys Ther 40:345-351

6. Briggs SL (2005) The role of fibronectin in fibroblast migration during tissue repair. J Wound Care 14:284-287

7. Chan BP, Fu S, Qin L, Lee K, Rolf CG, Chan K (2000) Effects of basic fibroblast growth factor (bFGF) on early stages of tendon healing: a rat patellar tendon model. Acta Orthop Scand 71:513-518

8. de Souza RR (2002) Aging of myocardial collagen. Biogerontology 3:325335

9. Del Buono A, Oliva F, Longo UG, Rodeo SA, Orchard J, Denaro V et al (2012) Metalloproteases and rotator cuff disease. J Shoulder Elbow Surg 21:200208

10. Domeij-Arverud E, Labruto F, Latifi A, Nilsson G, Edman G, Ackermann PW (2015) Intermittent pneumatic compression reduces the risk of deep vein thrombosis during post-operative lower limb immobilisation: a prospective randomised trial of acute ruptures of the Achilles tendon. Bone Joint J 97-B: 675-680

11. Frankewycz B, Krutsch W, Weber J, Ernstberger A, Nerlich M, Pfeifer CG (2017) Rehabilitation of Achilles tendon ruptures: is early functional rehabilitation daily routine? Arch Orthop Trauma Surg 137:333-340

12. Garofalo R, Mouhsine E, Borens O, Wettstein M (2004) Nonoperative treatment of acute rupture of the Achilles tendon: results of a new protocol and comparison with operative treatment. Am J Sports Med 32:1776-1777 author reply 1777

13. Goncalves Al, Rodrigues MT, Lee SJ, Atala A, Yoo JJ, Reis RL et al (2013) Understanding the role of growth factors in modulating stem cell tenogenesis. PLoS One 8:e83734

14. Gotoh M, Mitsui Y, Shibata H, Yamada T, Shirachi I, Nakama K et al (2013) Increased matrix metalloprotease-3 gene expression in ruptured rotator cuff 
tendons is associated with postoperative tendon retear. Knee Surg Sports Traumatol Arthrosc 21:1807-1812

15. Horstmann T, Lukas C, Merk J, Brauner T, Mundermann A (2012) Deficits 10years after Achilles tendon repair. Int J Sports Med 33:474-479

16. Ireland D, Harrall R, Curry V, Holloway G, Hackney R, Hazleman B et al (2001) Multiple changes in gene expression in chronic human Achilles tendinopathy. Matrix Biol 20:159-169

17. Juneja SC, Schwarz EM, O'Keefe RJ, Awad HA (2013) Cellular and molecular factors in flexor tendon repair and adhesions: a histological and gene expression analysis. Connect Tissue Res 54:218-226

18. Karousou E, Ronga M, Vigetti D, Passi A, Maffulli N (2008) Collagens, proteoglycans, MMP-2, MMP-9 and TIMPs in human achilles tendon rupture. Clin Orthop Relat Res 466:1577-1582

19. Koh IH, Kang HJ, Oh WT, Hong JJ, Choi YR (2017) Correlation between change in muscle excursion and collagen content after tendon rupture and delayed repair. J Orthop Surg Res 12:15

20. Kumar V, Abbas A, Fausto NR (2005) Cotran pathologic basis of disease, 7th edn. Philadelphia: Elsevier

21. Lantto I, Heikkinen J, Flinkkila T, Ohtonen P, Leppilahti J (2015) Epidemiology of Achilles tendon ruptures: increasing incidence over a 33year period. Scand J Med Sci Sports 25:e133-e138

22. Lemme NJ, Li NY, DeFroda SF, Kleiner J, Owens BD (2018) Epidemiology of Achilles tendon ruptures in the United States: athletic and nonathletic injuries from 2012 to 2016. Orthop J Sports Med 6:2325967118808238

23. Majewski M, Heisterbach P, Jaquiery C, Durselen L, Todorov A, Martin I et al (2018) Improved tendon healing using bFGF, BMP-12 and TGFbeta1 in a rat model. Eur Cell Mater 35:318-334

24. Minkwitz S, Schmock A, Kurtoglu A, Tsitsilonis S, Manegold S, Wildemann B et al (2017) Time-dependent alterations of MMPs, TIMPs and tendon structure in human Achilles tendons after acute rupture. Int J Mol Sci 18(10): 2199

25. Moller M, Lind K, Styf J, Karlsson J (2005) The reliability of isokinetic testing of the ankle joint and a heel-raise test for endurance. Knee Surg Sports Traumatol Arthrosc 13:60-71

26. Mullaney MJ, McHugh MP, Tyler TF, Nicholas SJ, Lee SJ (2006) Weakness in end-range plantar flexion after Achilles tendon repair. Am J Sports Med 34 $1120-1125$

27. Najafbeygi A, Fatemi MJ, Lebaschi AH, Mousavi SJ, Husseini SA, Niazi M (2017) Effect of basic fibroblast growth factor on Achilles tendon healing in rabbit. World J Plast Surg 6:26-32

28. Nguyen QT, Norelli JB, Graver A, Ekstein C, Schwartz J, Chowdhury F et al (2017) Therapeutic effects of doxycycline on the quality of repaired and unrepaired Achilles tendons. Am J Sports Med 45:2872-2881

29. Nilsson-Helander K, Silbernagel KG, Thomee R, Faxen E, Olsson N, Eriksson BI et al (2010) Acute achilles tendon rupture: a randomized, controlled study comparing surgical and nonsurgical treatments using validated outcome measures. Am J Sports Med 38:2186-2193

30. Nilsson-Helander K, Thomee R, Silbernagel KG, Thomee P, Faxen E, Eriksson Bl et al (2007) The Achilles tendon Total rupture score (ATRS): development and validation. Am J Sports Med 35:421-426

31. Norrbom J, Sundberg CJ, Ameln H, Kraus WE, Jansson E, Gustafsson T (2004) PGC-1 alpha mRNA expression is influenced by metabolic perturbation in exercising human skeletal muscle. J Appl Physiol 96:189-194

32. Olsson N, Nilsson-Helander K, Karlsson J, Eriksson BI, Thomee R, Faxen E et al (2011) Major functional deficits persist 2 years after acute Achilles tendon rupture. Knee Surg Sports Traumatol Arthrosc 19:1385-1393

33. Olsson N, Petzold M, Brorsson A, Karlsson J, Eriksson Bl, Silbernagel KG (2014) Predictors of clinical outcome after acute Achilles tendon ruptures. Am J Sports Med 42:1448-1455

34. Roos EM, Brandsson S, Karlsson J (2001) Validation of the foot and ankle outcome score for ankle ligament reconstruction. Foot Ankle Int 22:788-794

35. Silver FH, Horvath I, Foran DJ (2002) Mechanical implications of the domain structure of fiber-forming collagens: comparison of the molecular and fibrillar flexibilities of the alpha1-chains found in types I-III collagen. J Theor Biol 216:243-254

36. Svantesson U, Carlsson U, Takahashi H, Thomee R, Grimby G (1998) Comparison of muscle and tendon stiffness, jumping ability, muscle strength and fatigue in the plantar flexors. Scand J Med Sci Sports 8: 252-256

37. Svedman S, Westin O, Aufwerber S, Edman G, Nilsson-Helander K, Carmont MR et al (2018) Longer duration of operative time enhances healing metabolites and improves patient outcome after Achilles tendon rupture surgery. Knee Surg Sports Traumatol Arthrosc 26:2011-2020

38. Thomopoulos S, Parks WC, Rifkin DB, Derwin KA (2015) Mechanisms of tendon injury and repair. J Orthop Res 33:832-839

39. Tokunaga T, Karasugi T, Arimura H, Yonemitsu R, Sakamoto H, Ide J et al (2017) Enhancement of rotator cuff tendon-bone healing with fibroblast growth factor 2 impregnated in gelatin hydrogel sheets in a rabbit model. J Shoulder Elbow Surg 26:1708-1717

40. Wang Z, Li R, Zhong R (2018) Extracellular matrix promotes proliferation, migration and adhesion of airway smooth muscle cells in a rat model of chronic obstructive pulmonary disease via upregulation of the PIBK/AKT signaling pathway. Mol Med Rep 18:3143-3152

\section{Publisher's Note}

Springer Nature remains neutral with regard to jurisdictional claims in published maps and institutional affiliations.

\section{Submit your manuscript to a SpringerOpen ${ }^{\circ}$ journal and benefit from:}

- Convenient online submission

Rigorous peer review

- Open access: articles freely available online

High visibility within the field

- Retaining the copyright to your article

Submit your next manuscript at $\boldsymbol{\nabla}$ springeropen.com 